\title{
Strategic Option for Colleges to Create Good Sport Culture Atmosphere
}

\author{
Zhao Yang \\ College of Management Shenzhen Uniyersity \\ Shenzhen, China \\ zhgoat123@sina.com.cn
}

\begin{abstract}
Key words: sport culture; campus sport; culture atmosphere; happy sport
Abstract: As a method and form of the campus spirit construction, the sport culture forms an integral part of the campus culture. The understanding of the features and functions of the campus sport culture can play a positive driving role in developing the campus sport culture and advancing the college sport work. The colleges should adopt effective measures to constantly create the good sport culture atmosphere and finally boost the campus sport cultural activities, improving various teachers and students' health, study efficiency and working enthusiasm.
\end{abstract}

\section{Introduction}

The campus culture is a kind of group culture with the campus as space, the students and teachers as main body, the extracurricular activities as main contents, and the extensive cultural multi-science, multi-field communication and the special pace of life as basic form, which has the characteristics of times. In the meantime, the campus culture is also a multi-level and stereoscopic culture, which covers material culture, spiritual culture, life culture, art culture, behavior culture, sports culture, association culture, science and technology culture, psycho-culture, etc. As such, the sports culture is an important part of the campus culture. The campus sport culture is the cultural form existing in the campus, the specific environment. Fair competition, solidarity and cooperation, constantly striving to become stronger and always being confidence are the quintessence of the sport spirit, which have a strong unconsciously influence on the healthy development on the students with its special charm and function, and become the window of the campus culture. Specifically speaking, the campus sport culture is a specific sport culture atmosphere in school, the specific scope. It is the accumulation of the sport spirit treasure and material treasure created by people in the course of teaching and scientific and research practice, i.e., all the material wealth and spirit wealth as well as the sport notion and sport sense formed and owned by the teachers, students and staff in the activities such as the sport teaching, body building, athleticism, sport facility construction, etc. It is a kind of group culture with the students as main body, the extracurricular sport cultural activities as main contents, the campus as space, and the campus spirit as the main feature. Such specific culture atmosphere is linked with the school's cultivation target, school rules and disciplines, living style, etc. The campus sport culture is a specific culture phenomenon with deep contents and rich extension. It constitutes the campus culture group with the campus moral education, intellectual education, and aesthetic education cultures; and also constitutes the broach sport culture group with the competitive sport culture and mass sports culture. As a method and form of the campus spirit construction, the sport culture forms an integral part of the campus culture. 


\section{The features of the campus sport culture}

The construction of the campus sport culture may not only enrich the students' extracurricular culture and sport live, but also help to motivate the enthusiasm of the students to participate in the sports. It is the large stage to cultivate the life time sports. As a special cultural form, the sport culture has occurred in Chinese college campus for a long time. During the sport competitions and activities in the college campus, the broad teachers and students accept and spread the sport culture in an invisible way. It will produce great influence on the sport teaching, and play a determining role in further promoting the prosperity and development of the campus sport culture. Its features will be an integral part of the campus sport culture. Currently, Chinese college campus sport culture has the following significant characteristics.

a. The educational character of the campus sport culture

As a special cultural form, the campus sport culture has a rich educational function, which directly affects the sports consciousness of the undergraduates, and plays an invisible role in improving their quality as a whole. The campus sport culture acts in a direct and implicit way, and affects the students through the unconscious and non-specific psychic reaction mechanism, which is hidden, diversifying, easy-acceptable and initiative. Therefore, it is un-comparable by other education forms. For example, during Beijing Olympic Games, the undergraduate Olympic volunteers become "the most beautiful name card". The contemporary students participate in Olympic Games and make contribution. They improve themselves, and inherit the valuable spirit heritage in the service. Aiming at the group characteristics of the students, many colleges edify the students' behavior and morality through the sport culture arts, which enables the students to express themselves in the good sport culture atmosphere, cultivate the ability to distinguish the vulgar from the elegant, the beautiful from the ugly, and the good from the bad, establish the lofty and fine sportsmanship, regulate their behaviors, and optimize and perfect themselves in practice.

\section{b. The epochal character of the campus sport culture}

Being the same as other cultures, the campus sport culture shows the characteristic of an era, a country and a nation. It regulates the sport behavior of the teachers and students, and also influences their values. The era evolves and develops constantly, and there are different production modes in different historic periods. People always live in a specific environment, which produces a significant impact on the human kind. The campus sport culture created by the college teachers and students in practice also cannot live without the influence of such environment. Therefore, the specific character, contents and form show a distinct epochal character. In recent years, the establishment of socialism market economy mechanism provides a great development space for the campus sport culture. The colleges generally use "health first; education being the basic" as the guiding thought, fully develop the comprehensive qualities of the students, such as the sports, health and humanity, etc., promote the sunny sports to the climax, and enable the teachers and students to experience and enjoy the sports.

\section{c. The plurality of the campus sport culture}

Only by constantly integrating the positive connotation of modern human development and conforming to the sustainable development of the mankind can the modern sport culture become an integral part of people's lives. The outcome of the conflict among different campus sport culture spirit cores is to create a dynamic campus sport culture zoology system on basis of integrating the positive meanings of the campus social development, which changes with the times. At present, 
how to keep the necessary tension and balance between the secular, multiple and civilian orientation of the campus spirit culture and the thought unifying and country orientation of the main culture, is the important contents and objects of the campus sport culture.

d. The internationalism of the campus sport culture

Traditionally, the sport exists in certain national and regional culture. After the long historical accumulation, it forms its own special shape and developing model, which is the basis of the survival and development of the sports in different nations and regions. However, the sport, the common language of the mankind, realizes its own globalization accompanied by the economic globalization. The greatest progress of the current society is the constant improvement of the communication methods, especially that the television which can fully and truly spread various kinds of information greatly shortens the physical distance, enabling people to broaden their view and enhancing their ability to accept new things. With the modern media, the sport culture spread to everywhere of the world more extensively. For example, in order to improve the level of Chinese basketball league matches, China introduced its own league matches CBA which imitates NBA. The trend of the sport culture globalization make various parts of the college campus sport culture tend to be international. The leading western sport culture gradually permeates into the life of the teachers and students in different colleges under such circumstance.

\section{The strategic option create good sport culture atmosphere}

As part of the campus culture, the campus sport culture is a kind of social cultural phenomenon with profound meaning and rich extension. By illustration and analysis of the features of the campus sport culture, we can see its importance. With the development of Chinese society and the increasing of the economic level, the college should adopt effective measures to constantly build the good campus sport culture atmosphere to boost the campus sport cultural activities and improve the health, study efficiency and work enthusiasm of the teachers and students.

a. Energetically develop the campus sport culture construction and try to create good campus sport culture environment

The college sport education should not only reform in respect of the cultivation target, curriculum system, teaching method, teaching management system, etc., but also actively conduct the campus sports culture construction to try to build good campus sports culture environment. Adopting measures to construct the campus sports culture, is very important for cultivation the students' lifelong sports sense and developing the physical exercise habit. Specifically speaking, the colleges should do as follows: establish the idea that sports is a kind of culture; insisting on the principle that teaching "people" by "culture"; accelerating the construction of the campus sports facilities; improving the appetency of the sports material culture; taking the high level competing sporting events as the example; increasing the attention of the school internal group on the sports; promoting the reform of the sports teaching method; advocating the diversity of the sports teaching evaluation; and advancing the construction of the overall environment of the campus sports culture.

b. Increase the input to the construction of the campus sports material culture and satisfy various hobbies and interests of the teachers and students

The campus sports material culture is the collective calling of the external materialized form accumulated in the development of the school sports. It is the objective material guarantee of the campus sports culture construction, and the base and carrier for the existence and development of 
the campus spirit culture, such as the sports environment, place, equipment, books and materials, sports, teaching and competition regulations and systems, etc. The campus material culture is the indispensible material condition for the campus sports culture construction. In certain sense, the material culture is also the external expression of the development level of the campus sports culture. Therefore, it is important to enhance the construction of the material conditions of the campus sports culture, as well as reasonably use the existing sports facilities and goods (especially, it is very important to give full play of the college sporting place resources).

\section{c. Enhance the sports teaching reform and build the college sports club}

In recent years, there has been great change in the sports teaching in college. In order to adapt to the quickly changing social development, the sports should not be standstill. However, there are still factors unfavorable for the sports teaching, causing the sports teaching to grope the way forward. To accommodate the development of the society, the college should change the idea in respect of the sports; correct the teaching guidance thought and reform the overall sports curriculum to adapt the need of social development. The college sports teaching reform is a diversified system project, which depends on the joint effort of the school sports working staff as well as the support and cooperation of relevant departments. Only by always adhering to the guidance that health first and lifelong sports; targeting on quality education; improving the comprehensive quality the sports teachers; and constantly improving the teaching contents, method and model, can the students' personality and ability be better developed and become the qualified talent with the full development in morality, intelligence and physique. Training the students with the "lifelong sports sense" is an importance aspect of the teaching target of college sports. The traditional sport teaching is unable to fully satisfy the actual demand of the students. The college sports club is the product of the sports teaching reform, the organization form of which is in consistent with the requirement of the National Common College Sports Curriculum Teaching Guidance Outline. It plays an important role in training the students' interests in sports and having the exercise habit, and can satisfy the sports needs of the students of different levels and types.

d. Actively develop the campus sports competition games and greatly build the school sports delegation and take part in the interschool sports competition

The sport competition plays a special and irreplaceable role in developing the students' personality, training their ability, cultivating their taste and creating the sports atmosphere in school. The school sports work should be in line with the principle of basing on all the students; fully consider the features of popularity and consistence in respect of setting up the competition events, organization form, competing method and competing time, and develop the diversified sport competition. In the meantime, on basis of the sporting event level and the teaching conditions, the school should organize the campus sports delegation, enhance the training and participate in the interschool sports competition events. On one hand, it can promote the increase of the sports technology level; and one the other hand, it may improve the school reputation and find out the distance of the sports work, foster strengths and circumvent weaknesses to advance the school sports work and the campus sports culture construction onto a new level.

e. Train the high quality teacher team and improve the sports teaching quality

As the organizer and performer of the school sports work, the PE teacher is the hard core of the development of the campus sports culture activities. Their PE knowledge, ability, interests, hobbies, personality and professional advantages will have a deep impact on students. Therefore, constantly 
improving the knowledge and ability structure of the PE teachers, and advancing their comprehensive quality, especially the training of the competing ability, innovation ability and the coordination ability, is essential to the construction of the campus sports culture. It is necessary to give full play of different special skills, innovative teaching forms and methods of the PE teachers to improve the students' interests in the sports and fully activate the students' enthusiasm to participate in the campus sports culture events. The sports education is an important part of the undergraduate quality education. Only by the sports education and training, can the students fully improve the PE quality and have vigorous energy to study the knowledge and skills of other disciplines, and achieve the purpose of exercise and improving the physique and be sound in body and mind. Only by really improving the quality of college sports teaching, can the PE quality of the college students be really improved.

\section{Conclusion}

As an important part of the college campus culture, the college campus sport culture produces a huge impact on college sport. It constantly update and rich its contents with the development of the social culture. The understanding of the features and functions of the campus sport culture plays a positive role in promoting the development of the college sports work and enabling the teachers, students and staff to develop toward the direction of healthy, entertaining and competitive life. At present, the state promotes to enhance the construction of college campus culture. The colorful sport culture in the campus culture should not be ignored. The colleges should deeply understand the nature of the campus sport culture, adopt effective measures to greatly development the campus sport culture, create an active and colorful campus sport culture atmosphere, actively guide the teachers and students to participate in sports exercises, and form the exercise habit, which will benefit them all the life time.

\section{References}

[1] Wang Xiao,Wang Binghua: submitted to Journal of China Three Gorges University (Humanities \& SocialSciences) (2010)

[2] Zhang Yonghua: submitted to Sports humanistic sociology (2 0112$)$

[3] Shi Youkuan: submitted to Journal of Beijing Sport University (2013)

[4] Zhou Guiqin: submitted to Journal of Hubei Engineering University (2013)

[5] Xiong Douying: submitted to Journal of Sports and Science (2009)

[6]Wang Yuezhi, Li Zhaohe: submitted to Heilongjiang Researches on Higher Education (2011) 